\title{
Operating and optimising multifunctional urban flood protection - Lake PHOENIX Dortmund
}

\author{
Georg Johann ${ }^{1}$ and Alexander Hartung ${ }^{1}$ \\ ${ }^{1}$ Emschergenossenschaft, Kronprinzenstraße 24, 45128 Essen, Germany
}

\begin{abstract}
Lake PHOENIX in the heart of the city of Dortmund simultaneously fulfills many functions. In terms of city planning the lake is very significant. First and foremost it serves the local recreation of the citizens. The district of Hörde has been greatly upgraded and nowadays a very attractive construction area exists within the middle of the city. Ecologically, a 24.5-hectare mesotrophic shallow-water lake was created, which is sensitive to organic pollution due to its conditions. Third, this lake also fulfills a flood protection function. The river Emscher bypasses the Lake. Only if discharge is more than a $\mathrm{HQ}_{20}$, the Emscher flows into the lake. Lake PHOENIX offers a flood volume of 235,000 $\mathrm{m}^{3}$ and is able to reduce the flood discharge from $\mathrm{HQ}_{20}$ up to $\mathrm{HQ}_{100}$. During the first years of operation, it became evident that natural succession along the river causes many questions about the dimensioning and operation of the plant. This report describes the results of the intensive measurement campaign and the findings from the renewed. Last but not least, the effects on flood risk management are described and discussed..
\end{abstract}

\section{Lake PHOENIX: Genesis and tasks}

The city of Dortmund is geographically located in the east of the Ruhrgebiet, but from the population's point of view it is right in his heart, and this is not only due to the world-famous soccer club. In the course of industrialisation, the steel industry also became the mainstay of the economic development of the Ruhrgebiet and this continued well into the 20th century. With the last steel crisis in the 1990s, the economic restructuring in the Ruhrgebiet away from heavy industry began. The steelworks in the Dortmund district of Hörde were closed in 2001. The sale of the factory to a Chinese investor left behind a highly polluted 210 ha of two-part fallow land.

After some consideration of how these areas in the immediate vicinity of Dortmund city centre could be reactivated, it was decided, among other things, to create an artificial shallow water lake of around 24 ha in size. This lake serves the recreation of the citizens and also contains a residential area including a service sector and finally functions as a retention basin to increase the flood protection for the city of Dortmund.

With a length of around 1200 metres and a width of 320 metres, this artificial water body has an average depth of only 3 metres. It is therefore very sensitive to the input of nutrients, and many precautions have been taken to prevent eutrophication during the filling phase but also later on (Petruck \& Sommerhäuser, 2014). With a still mesotrophic status this seems to have been successful also in the 9th year after the flooding. The attractive location on a lake with crystal-clear water and the immediate proximity to the service sector has sparked an unprecedented construction boom in the residential areas around the lake.

Flood protection is ensured by a 1 meter high storage lamella, which covers a volume of 235,000 cubic metres. The small river Emscher bypasses the lake so that the water quality of the lake is not worsened.

\section{Function of lake PHOENIX in flood protection}

Lake PHONIX is located at the upper reaches of the densely built-up city of Dortmund and is an important element of flood protection as part of a series-connected system of flood control reservoirs (figure 1).

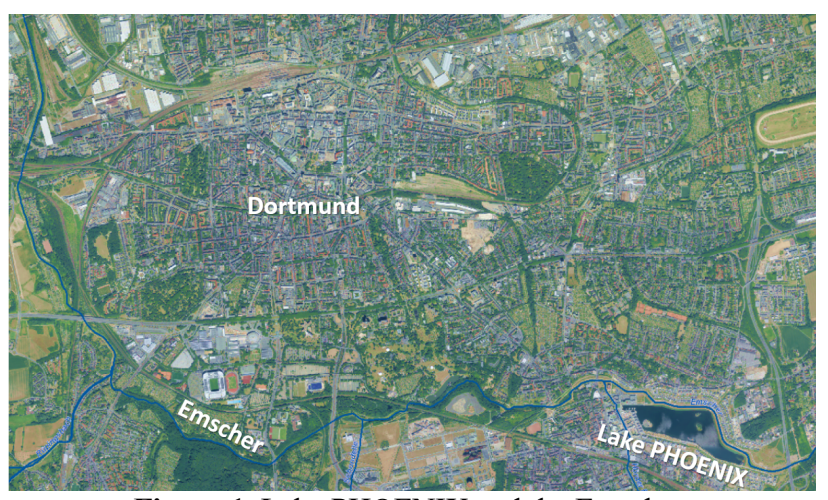

Figure 1. Lake PHOENIX and the Emscher in the upstream of Dortmund

${ }^{a}$ Corresponding author: johann.georg@eglv.de

DOI 10.3311/FLOODRisk2020.3.7 
Flood management of the waterboard Emschergenossenschaft is supported by the operational online flood forecast of the Emscher, which continuously provides an up-to-date discharge forecast. On the basis of a flood information system, the forecast products of the German Weather Service as well as online measurements of precipitation and runoff are integrated and enable predictive flood calculations. For this purpose, online ensemble calculations are carried out and the flood situation is daily assessed by an expert (Johann et al., 2017).

Lake PHOENIX is located at the upper reaches of the Emscher and has a catchment area of $28 \mathrm{~km}^{2}$, which is, however, densely built up. Thus fast, high flood waves flow are common (Hartung \& Johann, 2016). The Lake PHOENIX is a dam with a constant volume of $600,000 \mathrm{~m}^{3}$. The Emscher flows parallel to the lake and is throttled by a three-bladed weir system to an $\mathrm{HQ}_{20}$, which corresponds to a discharge of $15 \mathrm{~m}^{3} / \mathrm{s}$. In times of discharges larger than $15 \mathrm{~m}^{3} / \mathrm{s}$ the water flows over a dike overflow into the lake. The 24 ha water surface of Lake PHOENX can be raised by up to one meter without any risk for the adjacent areas. At a $\mathrm{HQ}_{100}$, a discharge of $25 \mathrm{~m}^{3} / \mathrm{s}$ of the Emscher, the retention volume of the Lake PHOENIX is exhausted (figure 2). At this stage the discharge larger than $\mathrm{HQ}_{100}$ is led into the Emscher via a spillway that is located in the downstream of the lake.

\section{Natural succession of the Emscher vs. flood protection function}

As the lake also pursues ambitious ecological objectives, it is a declared management objective to limit the actual use of this volume to the necessary extent. This is to avoid unnecessarily impairing the ecology of the Lake PHOENIX pond by the nutrients contained in the flood discharge of the Emscher, especially phosphate and sediment. The Emschergenossenschaft sets this goal through a coordinated management concept for Lake PHOENIX (Möhring et al., 2014). Under no circumstances must water from the Emscher reach the lake with a lower discharge than with a $\mathrm{HQ}_{20}$.

With the construction of the Lake PHOENIX, the Emscher itself was also ecologically transformed. The Emscher shall develop naturally. The characteristics of the developing vegetation in the flood plain of the Emscher were estimated by aquatic ecologists.

The prognosis of the vegetation that will occur is associated with significant uncertainties, because the Emscher was a concreted open sewer before the redesign. The resulting vegetation depends, among other things, on the nutrient content of the water and soil, the flow velocities and the shading. This is a complex set of factors that influence each other and change dynamically over time.

The predicted vegetation is implemented in the hydraulic model. In this case a one-dimensional hydraulic model that can be used. The vegetation is considered in each cross-section that, in total, describe the watercourse.
The height of the overflow into the lake was dimensioned with this hydraulic plan scenario.

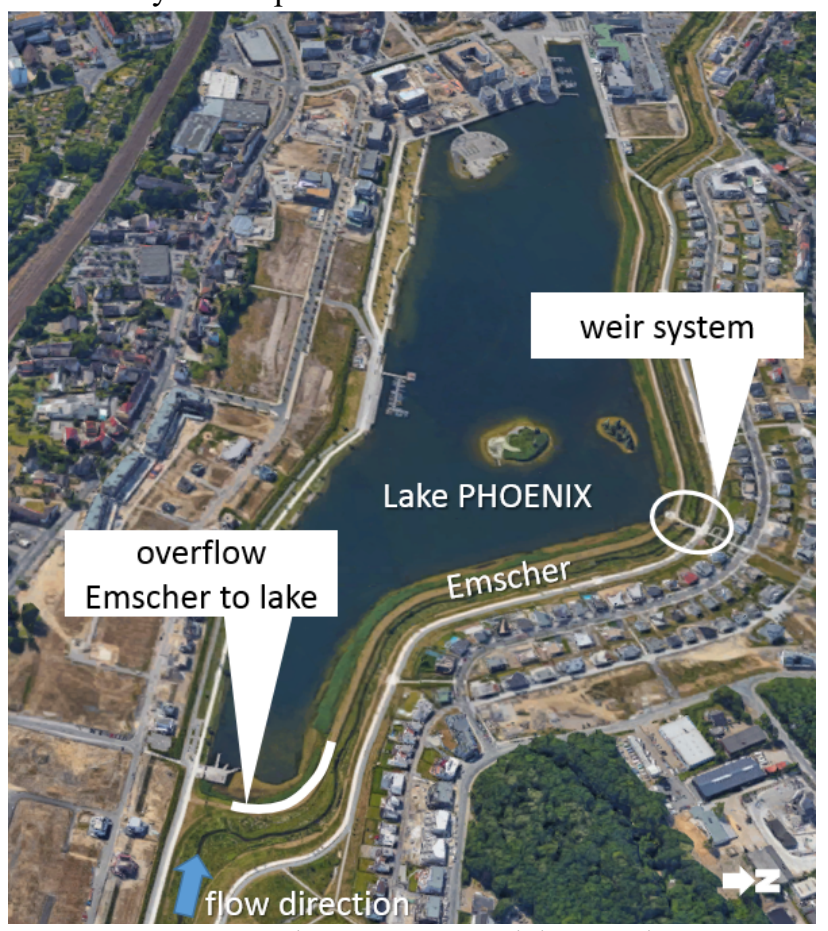

Figure 2. Lake PHOENIX and the Emscher weir system and overflow

After the restoration of the Emscher, along the Lake PHOENIX, dense vegetation came up both in the riverbed and in the floodplain. In wide areas along the shore reedbeds grew, which caused a significant narrowing of the watercourse (figure 3 ). In addition to shrubs, the river plain is also home to tall perennial meadows. This vegetation is denser than predicted in the planning. Also the tall perennials and reeds have such thick trunks that they do not buckle if a flood occurs. This means that the flow velocities are significantly reduced by the vegetation. This reliably increases water levels during floods in the Emscher and the lake could be filled even with smaller discharges than an $\mathrm{HQ}_{20}$.

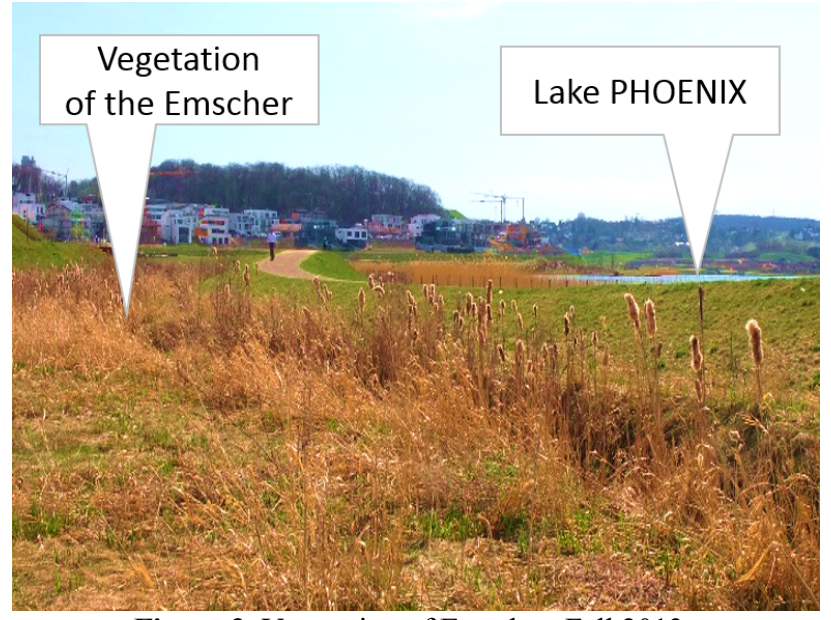

Figure 3. Vegetation of Emscher, Fall 2013, at Lake PHOENIX 
In September 2013, there was a minor flood event, during which a discharge of $6.4 \mathrm{~m}^{3} / \mathrm{s}$ was measured. Figure 4 shows the water level in the area of the overflow during this event. The water level is about $50 \mathrm{~cm}$ below the overflow.

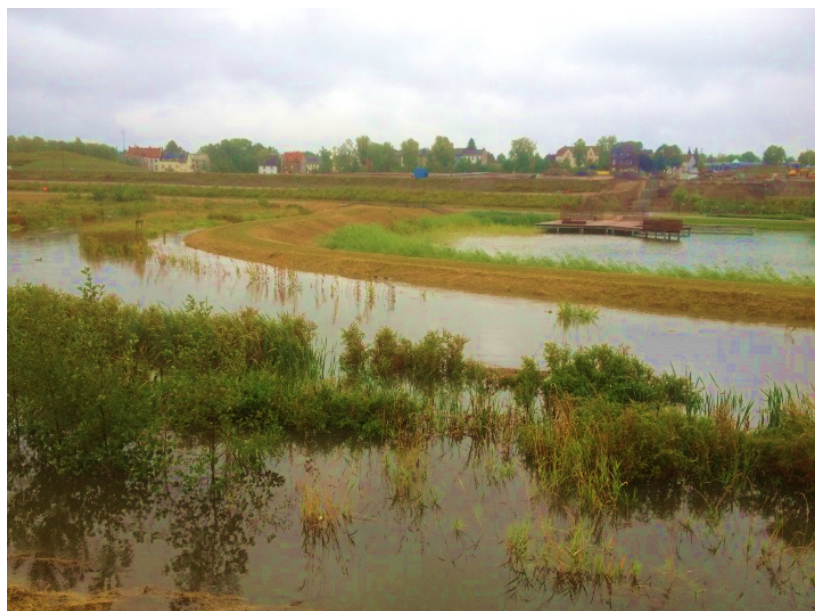

Figure 4. Emscher and Lake PHOENIX, Sep. 2013

During this flood event, flow velocity measurements were also carried out. They showed, due to the shallow bed slope and the vegetation, a very low flow velocity in the area under consideration, especially in the overgrown areas of the floodplain. In order to guarantee flood safety and the lake's ecology, it became clear, that, the vegetation had to be reduced. For this purpose, the hydraulic model had to be updated by implementing the converted condition of the Emscher and calibrated. Therefore, a water level and discharge measurement system has been installed.

\section{Solution concept: From measurement to modeling}

To calibrate the hydraulic model, continuous measurements of the Emscher are necessary, so that the rapidly occurring flood waves can be recorded without interruption. Due to the vegetation in the Emscher, which changes from year to year and with the seasons, no reliable water level-discharge relationship can be determined. For this reason, both water level and flow velocity must be measured continuously to determine the actual associated discharge. With these data the hydraulic model can be calibrated reliably.

With the construction of Lake Phoenix, two gauging stations were built and an existing one was integrated. About $1.4 \mathrm{~km}$ above the Bellevue weir system is the upstream gauging station named "Adelenstraße" for Lake Phoenix situated. This gauging station was built while this section of the Emscher was reconstructed in 2011. Here, the water level is measured and the flow in the Emscher is calculated via a rating curve. However, this rating curve is unaffected by vegetation problems further below.

There is a basin gauging station in Lake Phoenix which records the water level of the lake. The water level in the lake provides an overview of the filling level of the basin and thus also information about the available retention space.

The downstream gauging station is $0.9 \mathrm{~km}$ below the weir system, where both the water level and the velocity are recorded. The downstream station "Am Magazin" has a developed cross-section and is, like the upstream station, unaffected by vegetation.

The data from all these three gauging stations and the upstream retention basins converge in the operations centre of Lake Phoenix See and is used there to control the weir system. The decisive factor is the discharge at the downstream station "Am Magazin", so that the threshold of $15 \mathrm{~m}^{3} / \mathrm{s}$ for the areas below is maintained.

In addition to these gauging stations, the upstream retention basin named "Nagelpötchen" is located about 3 $\mathrm{km}$ above Lake Phoenix. Due to its significantly lower storage volume, only the water level in the basin is measured here.

\section{Measurement concept and realisation}

During the course of the event in September 2013, inconsistencies occurred in the values of the recorded discharge. This was further investigated in the course of a 3-year measurement campaign. Three additional measuring points were installed (figure 5).

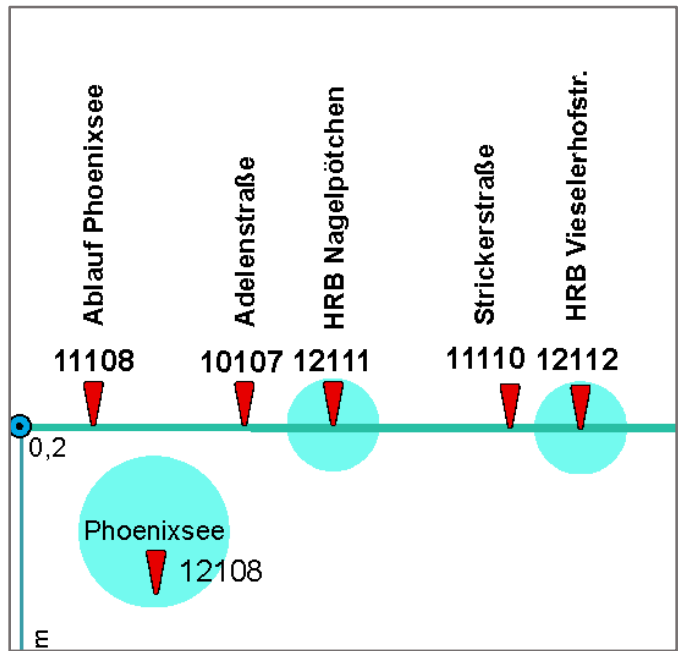

Figure 5. Measuring points at the Emscher

The first was installed approx. $50 \mathrm{~m}$ below the outlet structure of the retention basin "Nagelpötchen". The second additional measuring point was set up directly at the "Adelenstraße" gauge in order to improve the rating curve of the "Adelenstraße" gauge through additional velocity measurement.

The third measurement was built in $100 \mathrm{~m}$ above the Bellevue weir system. From this point on, the main tributaries like storm water retention basins are all present, so that the discharge at the gauge "Am Magazin" can be checked additionally.

These three velocity measurements were installed in April 2016 and operated until February 2020. Although the hydrological situation in these years was characterised by an extraordinary rare flood situation, some smaller floods could be obtained for calibration in the lower flood range. 
Uninfluenced by this, sufficient data for the mid and low water range were of course available. In total, the rating curve at the "Adelenstraße" gauge was slightly changed, the measurements of the ultrasonic system at the gauge "Am Magazin" were also improved. In addition, it was also possible to analyse and record more precisely the run-off behaviour of the stormwater retention basin located in between.

\section{Optimising the system - ensuring flood protection function while guaranteeing ecological concerns}

The aim of system optimisation is to adapt the overall vegetation situation, taking into account both ecological and hydraulic concerns. For this purpose, a hydraulic model is required that can depict the vegetation as realistically as possible. The planning is then also reliable, as there is no need to speculate about the type of vegetation, as was necessary at the time of planning. For this purpose, different vegetation parameters were agreed upon for calibration in the hydraulic model for the different seasons. This allows the sensitivity of the seasonal vegetation change to flood runoff to be analysed.

For the vegetation in summer and autumn, the slow flow velocities could no longer be reproduced with hydraulic-physical vegetation parameters that could be justified. Therefore, the low vegetation speed is modelled by defining ineffective flow areas. For this purpose, in all cross sections along the Lake PHOENIX the complete river plain areas to the left and right of the middle water bed are defined as hydraulically ineffective, so that these areas only function for retention but not as a section that discharges water (figure 6).

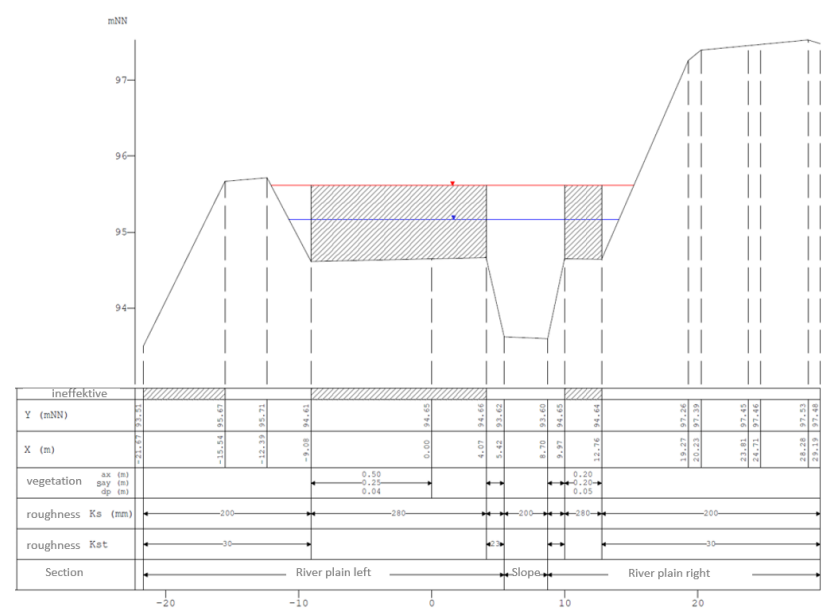

Figure 6. Cross section of the Emscher at the overflow to Lake POHENIX: Water level at with ineffective section; $6,4 \mathrm{~m}^{3} / \mathrm{s}-$ blue; $11.4 \mathrm{~m}^{3} / \mathrm{s}$ - red

A new calculation with a discharge of $6.4 \mathrm{~m}^{3} / \mathrm{s}$ provides water levels in the order of the documented event. As a result of the calculation with $6.4 \mathrm{~m}^{3} / \mathrm{s}$ at the profile, Figure 6 shows a distance to the overflow of approximately $50 \mathrm{~cm}$. The plausibility of this calculation variant was also confirmed by the photographically documented water level situation (figure 4). Figure 6 shows that the performance of the design profiles, including the definition of hydraulically ineffective areas in the area of the overflow, is then $11.4 \mathrm{~m}^{3} / \mathrm{s}$.

With the calibrated hydraulic model, the vegetation situation as a whole is adjusted, taking into account both ecological and hydraulic concerns. A new maintenance and development plan is, therefore, being developed (Emschergenossenschaft, 2017). A planning process is established for this purpose: First, the hydraulic requirements are calculated, which vegetation is possible in the flood plain. This variant is compared with the ecological requirements and, based on this, a maintenance and development plan for the Emscher is designed. This plan is in turn hydraulically checked (figure 7).

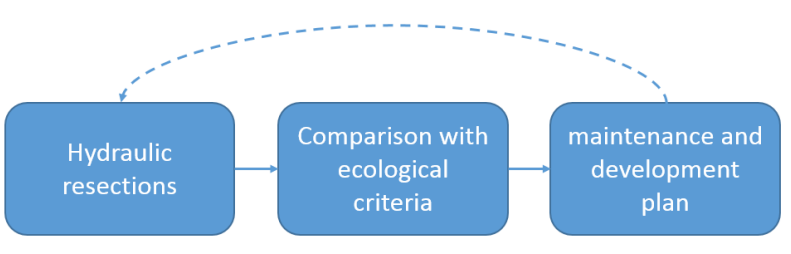

Figure 7. planning process for maintenance and development plan

To optimize the possible vegetation, the first hydraulic variant is calculated. Here only reed bed along the middle water bed is considered as high shrup area or landscape lawn. The areas with reed bed were also defined as hydraulically ineffective areas in this variant, since a restricted flow rate is to be expected there as well. However, since the flow capacity is largely exhausted, there is no room for further growth in the cross section.

The maintenance and development plan shows different sections of vegetation based on hydraulic requirements. These different vegetation sections must be maintained either regularly or occasionally. There are also sections with natural vegetation (figure 8).

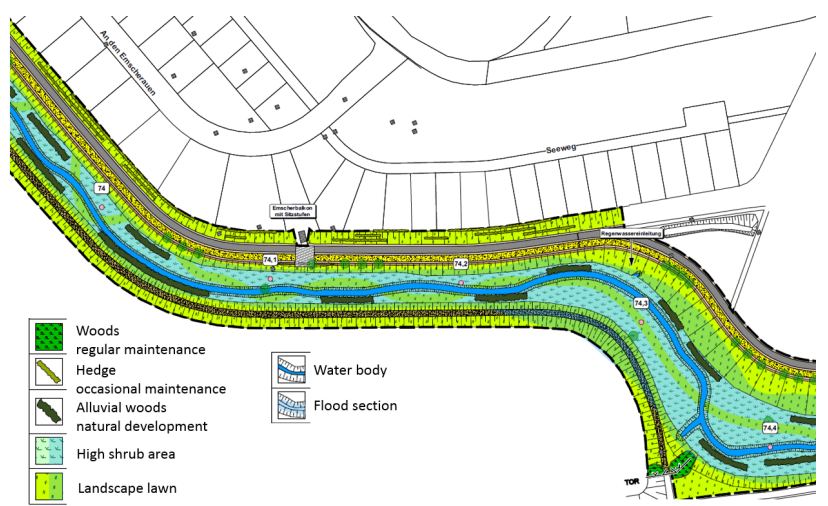

Figure 8. Part of the maintenance and development plan of the Emscher at Lake POHENIX

\section{Conclusion}

The multifunctional use of flood protection facilities requires an integral approach. Therefore, the close connection between modelling and measurement is evident for such questions. A densification of the 
measuring network by additional measuring points increases the data basis for the modelling. It gives a better insight into the processes taking place, a better understanding of the system and thus a more plausible modelling, which can then operate with fewer assumptions. Thus, accurate data can be determined, which ultimately ensures cost-efficient and targeted planning.

\section{References}

1. Emschergenossenschaft (2017): Emscher Oberlauf und Hörder Bach im Bereich Phoenixsee Emscher von km 72,60 bis $\mathrm{km} \mathrm{74,84} \mathrm{Hörder} \mathrm{Bach} \mathrm{von} \mathrm{km} 0,00$ bis $\mathrm{km}$ 0,58 in Dortmund. Pflege - und Entwicklungsplan. Essen

2. Hartung, A. \& Johann, G. (2016): How to manage flood forecasting in a catchment with high flood risk experiences from the Emscher. FLOODrisk 2016 - 3rd European Conference on Flood Risk Management, Lyon

3. Johann, G., Pfister, A. \& Teichgräber, B. (2017): Hoch-wasservorhersage für die Deichverteidigung im Emscher- und Lippegebiet. Korrespondenz Wasserwirtschaft 10/17: $641 \mathrm{ff}$

4. Möhring, B., Korte, T., zur Mühlen, P.,Petruck, A., Pfister, A.\& Sommerhäuser, M. (2014): Der PHOENIX See - Highlight des Strukturwandels im neuen Emschertal. Korrespondenz Wasserwirtschaft 7/1: $17 \mathrm{ff}$

5. Petruck, A. \& Sommerhäuser M. (2014): Lake Phoenix and River Emscher- Design and Management of an Artificial Urban Shallow Lake and a Lowland River, Presentation at the World Lake Conference 2011, Austin, TX, unpublished. 